\title{
Isolated posterior capsular rupture following blunt head trauma
}

This article was published in the following Dove Press journal:

Clinical Ophthalmology

28 November 2014

Number of times this article has been viewed

\author{
Ahmad M Mansour \\ Mahmoud O Jaroudi \\ Rola $\mathrm{N}$ Hamam \\ Fadi C Maalouf \\ Department of Ophthalmology, \\ American University of Beirut, \\ Beirut, Lebanon
}

\begin{abstract}
Closed-globe traumatic cataract is not uncommon in males in the pediatric age group. However, there is a relative paucity of literature on isolated posterior lens capsule rupture associated with closed-globe traumatic cataract. We report a case of a 6-year-old boy who presented with white cataract 1 day after blunt trauma to the forehead associated with posterior capsular rupture that was detected by B-scan ultrasonography preoperatively. No stigmata of trauma outside the posterior capsule could be detected by slit-lamp exam, funduscopy, and optical coherence tomography. Phacoemulsification with posterior chamber intraocular lens implant was performed 24 hours after trauma, with the patient achieving 6/6 visual acuity 1 week and 6 months after surgery. Our case is unique, being the youngest (amblyogenic age) to be reported, with prompt surgical intervention, and with no signs of trauma outside the posterior capsule.

Keywords: posterior capsule rupture, forehead trauma, traumatic cataract, pediatric cataract
\end{abstract}

\section{Introduction}

Blunt ocular trauma frequently leads to damage of the cornea, lens, and retina. However, there is scarce literature ${ }^{1-15}$ on isolated posterior lens capsule rupture (PCR) following blunt ocular trauma. We present the case of a child who developed an isolated oval defect in the posterior lens capsule after blunt trauma with rapid cataract formation.

\section{Case report}

Our case is a 6-year-old boy who sustained direct minor trauma to the left forehead. He was playing at home with his sister and swirling in a circular fashion when he slipped and hit his forehead against the ground. The following day, he reported blurring of vision in the left eye and his parents noticed a white left pupil. Twenty-four hours following the incident, examination of the right eye was normal and the left eye had hand motion vision. Intumescent cataract was evident by slit-lamp examination (Figure 1). The cornea was clear, the anterior chamber was deep and quiet, the pupil was round and reactive, and the anterior lens capsule was intact. Intraocular pressure measured $14 \mathrm{mmHg}$ in the right eye and $16 \mathrm{mmHg}$ in the left eye. Gonioscopy revealed a normal angle without angle recession. The media opacity precluded exam of the posterior segment. B-scan revealed a flat retina, quiet vitreous, and a breached posterior capsule centrally (Figure 2). Computerized tomography scan of brain was negative for skull fracture or intracranial bleed. Since the patient was in the amblyogenic age, cataract surgery was performed within hours of presentation.

Surgery was started with trypan blue staining of anterior capsule, anterior circular capsulorhexis, and avoiding hydrodissection to prevent expansion of PCR. Slow aspiration of lens matter with the phacoemulsification probe was performed under low settings of bottle height, irrigation, and aspiration. After aspiration of two-thirds of the lens content, 


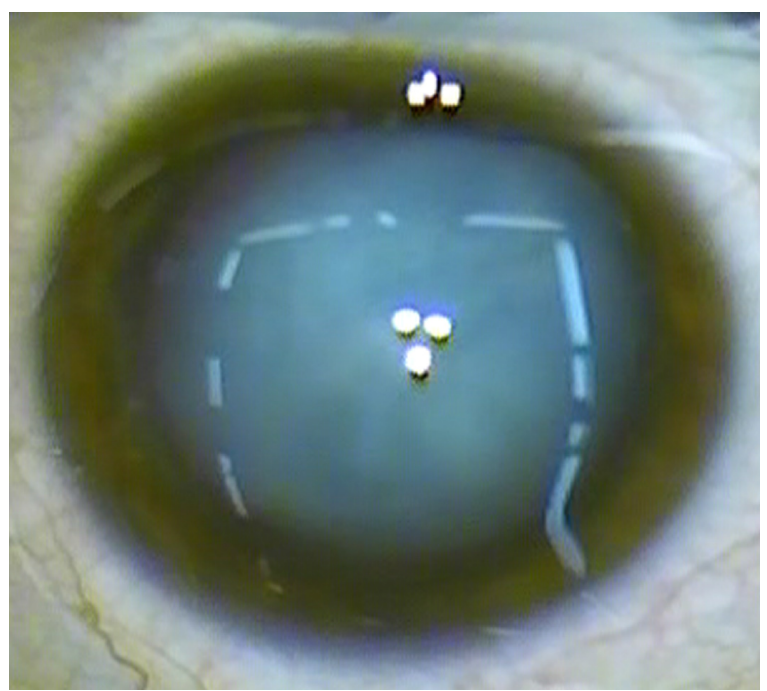

Figure I Mature white cataract of the left eye I day after blunt trauma to the forehead.

a very large, oval-shaped central posterior capsular rent was exposed (Figure 3). Anterior vitrectomy was performed, followed by cortex aspiration with the vitrector. Although onepiece foldable intraocular lens implantation in the capsular bag was initially thought feasible, the intraocular lens had a tendency to dislodge into the vitreous cavity, necessitating subsequent fixation in the sulcus without further optic capture (Figure 4). Intracameral carbachol was applied at the end of the surgery. One week postoperatively, uncorrected visual acuity was 6/6 (20/20). The patient had normal funduscopy and spectral-domain optical coherence tomography of the posterior pole. Visual acuity stabilized at 6/6 (20/20) over 14 months of follow-up with well-centered intraocular implant.

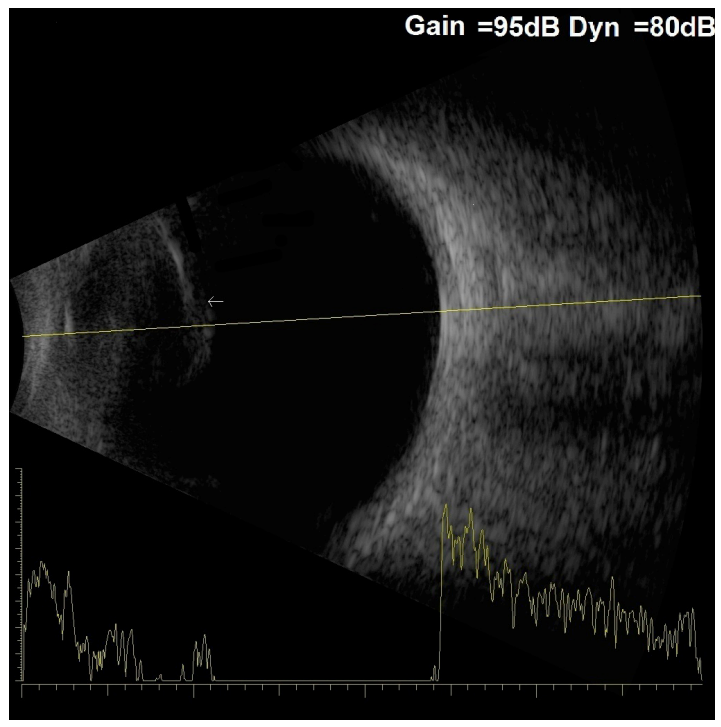

Figure 2 Posterior capsular defect (arrow) is evident by B-scan of the left eye.

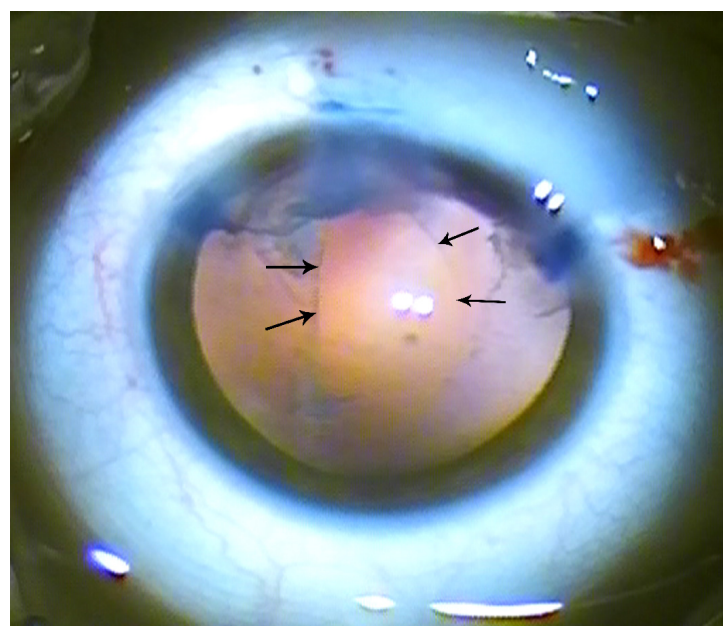

Figure 3 Large oval defect of the posterior lens capsule of the left eye as noted after aspiration of most of the lens content.

Note: Arrows delineate the edge of the ruptured posterior capsule.

\section{Discussion}

Isolated PCR in the event of blunt trauma appears rarely (Table 1). ${ }^{1-15}$ Our patient presented unique features that differ from those reported in the literature (Table 1) in several respects: he is the youngest patient in the literature (6 years) with PCR; his visual loss was rapid in onset and very severe to the level of hand motion (unlike a gradual decrease in other cases); he underwent "immediate" (24 hours after trauma) surgery to prevent amblyopia (unlike the several days to weeks in other cases); and his ocular findings were uniquely restricted to PCR with absence of iritis, hyphema, Vossius ring, iris sphincter tear, angle recession, or posterior pole trauma (funduscopic and tomographic).

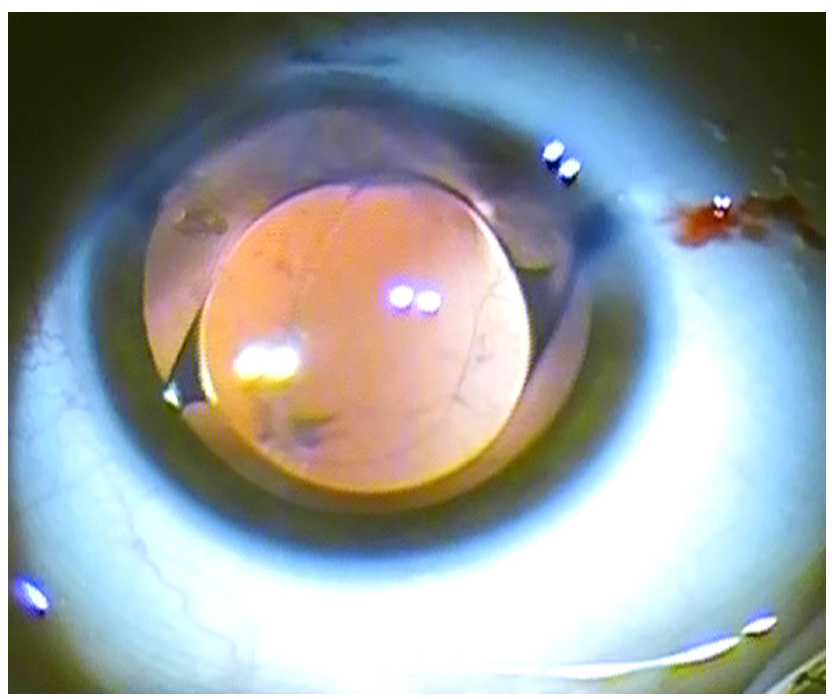

Figure 4 Well-centered acrylic intraocular lens placed in the sulcus at the end of surgery. 


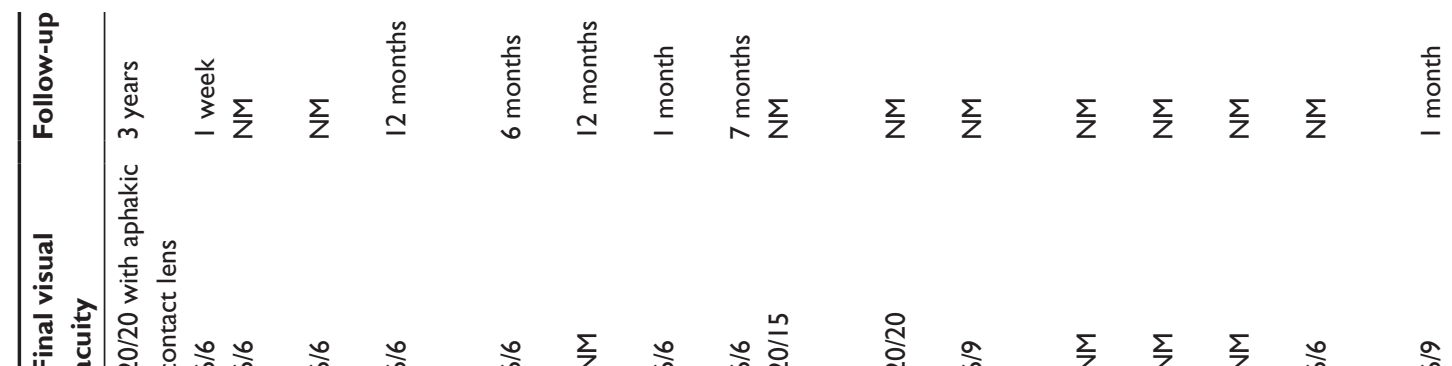

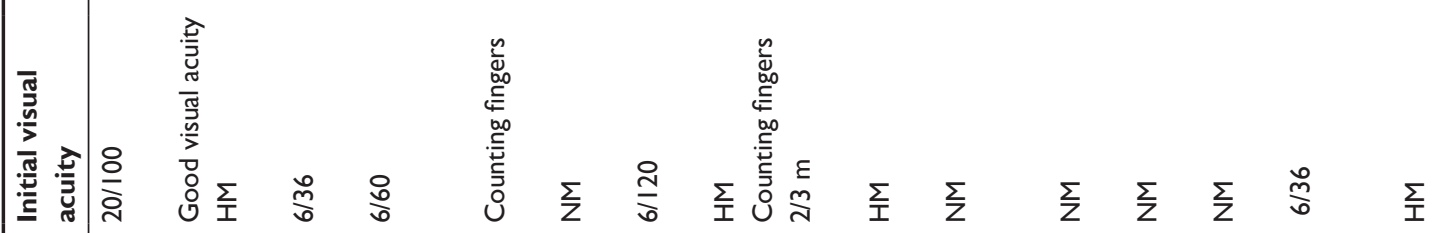

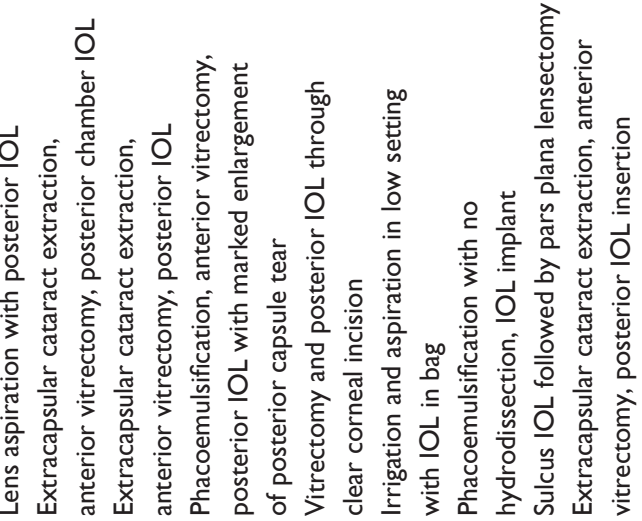
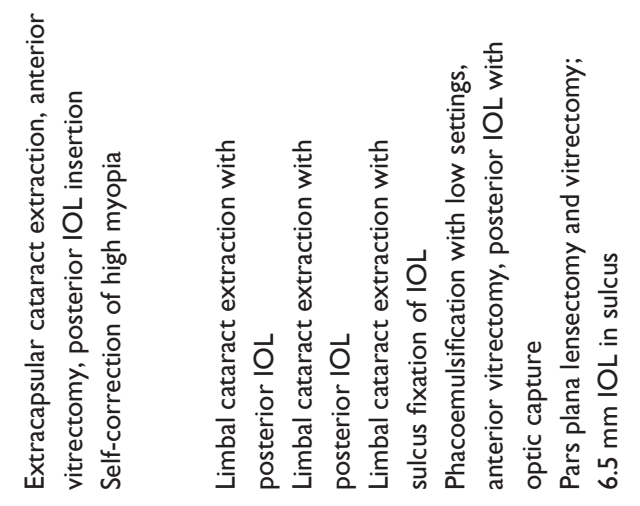

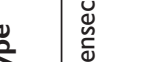
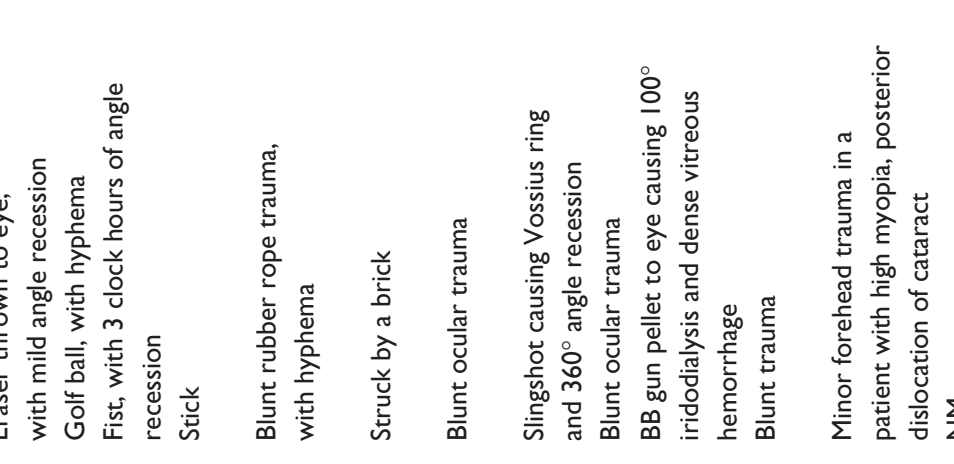

tᄒ

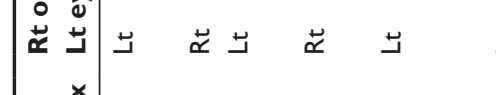

$\exists$

$ت \quad 5$

$\exists \quad \exists \quad \sum \quad \sum \ddot{\Sigma} \quad$

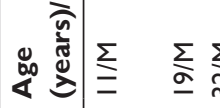

응

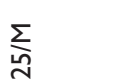

$\underline{\sum} \underline{\underline{3}}$

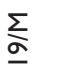

$\sum \quad \sum \underset{j}{i} \underline{\underline{m}}$

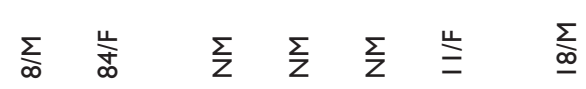

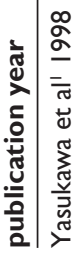

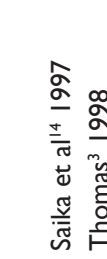

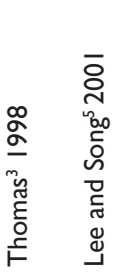

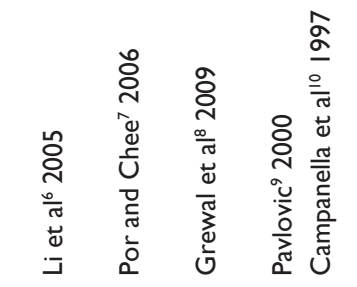

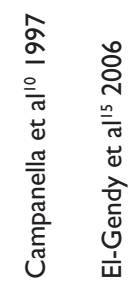

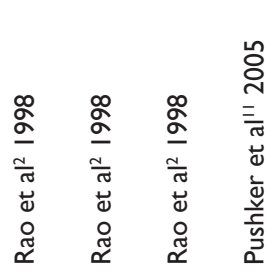

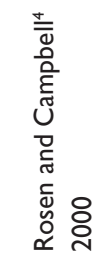


Table 2 Proposed mechanisms for isolated posterior capsular rupture following forehead trauma

I. Compression injury leads to equatorial elongation and stretching of strong zonules, which leads to thinning or stretch of posterior capsule.

2. Coup injury: direct contusion from rapid focal indentation of the cornea onto the lens.

3. Contrecoup injury: rapid anteriorly directed rebound of vitreous can lead to the posterior capsule bursting open.

4. Wieger's ligament acts like a "battering ram", using the contrecoup forces to press on the posterior capsule: rapid compression and expansion forces directed along the anteroposterior axis of the eye may avulse the central region of the posterior lens capsule. Wieger's ligament represents $8 \mathrm{~mm}$ in diameter of central lenticulo-vitreous adhesion that is most adherent in the midperipheral region of the lens of the young.

5. Forehead trauma: I) eye protruded beyond the frontal line with the injury to the forehead hitting the cornea (our case); 2 ) in deep set eyes, the highly myopic eye renders the cornea at the level of the forehead-cheek line. ${ }^{12}$

PCR can be diagnosed preoperatively by B-scan ultrasonography. ${ }^{6}$ Echography with a $20 \mathrm{MHz}$ probe was found to be an accurate and sensitive imaging modality for detection of PCR in a large series of traumatic cataracts (41 open-globe injuries and two closed-ocular injuries). ${ }^{13}$ Other diagnostic modalities, such as Scheimpflug imaging, can be especially helpful in delineating the extent of PCR, amount of residual nucleus and cortex, and presence or absence of vitreous prolapse in the anterior chamber. ${ }^{8}$

When PCR occurs, management depends on several parameters, such as the extent and location of the tear, the amount of residual nucleus and cortex, and the presence of vitreous in the anterior chamber. Traditionally, pars plana lensectomy was the preferred approach for managing such cases. ${ }^{1-3}$ More recently, surgeons have adopted a method

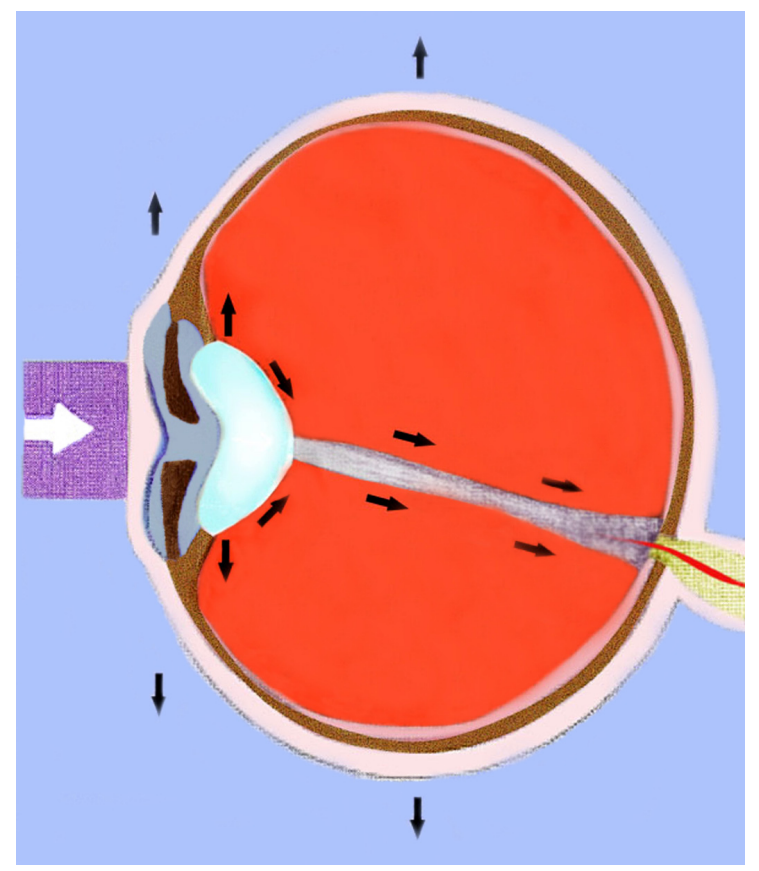

Figure 5 Artistic rendition of the most probable cause of posterior capsule rupture: equatorial globe and zonular stretch as well as anteroposterior pull by Wieger's ligament.

Note: The black arrows represent the tractional forces generated by the blunt trauma (white arrow). involving a clear corneal incision, phacoemulsification, and intraocular lens implantation in the capsular bag, with excellent visual outcome. ${ }^{7,9,11}$ Pars plana vitrectomy with lensectomy is reserved for cases of extensive posterior capsular rupture, marked vitreous prolapse, or significant zonular instability.

The mechanism of blunt trauma-induced blowout PCR in children can be explained by a combination of forces (Table 2; Figure 5):10,16 1) equatorial elongation of the globe following blunt trauma leads to stretch of zonules and posterior capsule; 2) anteroposterior vector force to the posterior capsule from direct trauma; 3) preferential rupture of elastic posterior capsule because the zonules are strong in children. ${ }^{7} \mathrm{We}$ postulate that the anatomy of the bony orbit around the globe might play a pivotal protective role in cases of head trauma. Our patient had a shallow orbital rim, making the globe more vulnerable to injury upon direct forehead trauma.

This case of isolated PCR and 17 cases in the literature establish PCR as a distinct clinical entity with diagnostic echographic findings, special surgical management strategy, and good visual outcome. ${ }^{1-11,14,15}$

\section{Acknowledgments}

Written informed consent was obtained from the patient's family for publication of this case report and any accompanying images. A copy of the written consent is available for review by the editor-in-chief of this journal.

\section{Author contributions}

AMM made substantial contributions to conception and design; MOJ made substantial contributions to acquisition, analysis, and interpretation of data; RNH and FCM was involved in initial conception and data collection. All authors were involved in drafting the manuscript and revising it critically for important intellectual content, and all authors gave final approval of the version to be published.

\section{Disclosure}

The authors report no conflicts of interest in this work. 


\section{References}

1. Yasukawa T, Kita M, Honda Y. Traumatic cataract with a ruptured posterior capsule from a nonpenetrating ocular injury. J Cataract Refract Surg. 1998;24:868-869.

2. Rao SK, Parikh S, Padhmanabhan P. Isolated posterior capsule rupture in blunt trauma: pathogenesis and management. Ophthalmic Surg Lasers. 1998;29:338-342.

3. Thomas R. Posterior capsule rupture after blunt trauma. J Cataract Refract Surg. 1998;24:283-284.

4. Rosen WJ, Campbell DG. Posterior capsule rupture after a paint-pellet injury. J Cataract Refract Surg. 2000;26:1422-1423.

5. Lee SI, Song HC. A case of isolated posterior capsule rupture and traumatic cataract caused by blunt ocular trauma. Korean J Ophthalmol. 2001;15:140-144.

6. Li KK, Groenewald C, Wong D. Management of traumatic posterior capsular rupture: corneal approach with high speed vitrector. $J$ Cataract Refract Surg. 2005;31:1666-1668.

7. Por YM, Chee SP. Implantation of foldable intraocular lens with anterior optic capture in isolated posterior capsule rupture. $J$ Cataract Refract Surg. 2006;32:707-708.

8. Grewal DS, Jain R, Brar GS, Grewal SP. Scheimpflug imaging of pediatric posterior capsule rupture. Indian J Ophthalmol. 2009;57:236-238.
9. Pavlovic S. Epilenticular intraocular lens implantation in traumatic cataract with a ruptured posterior capsule. Am J Ophthalmol. 2000;130: 352-353.

10. Campanella PC, Aminlari A, DeMaio R. Traumatic cataract and Wieger's ligament. Ophthalmic Surg Lasers. 1997;28:422-423.

11. Pushker N, Sony P, Khokhar S, Vardhan P. Implantation of foldable intraocular lens with anterior optic capture in isolated posterior capsule rupture. J Cataract Refract Surg. 2005;31:1457-1458.

12. Angra SK, Vajpayee RB, Titiyal JS, Sharma YR, Sandramouli S, Kishore K. Types of posterior capsular breaks and their surgical implications. Ophthalmic Surg. 1991;22:388-391.

13. Tabatabaei A, Kiarudi MY, Ghassemi F, et al. Evaluation of posterior lens capsule by $20 \mathrm{MHz}$ ultrasound probe in traumatic cataract. Am J Ophthalmol. 2012;153:51-54.

14. Saika S, Kin K, Ohmi S, Ohnishi Y. Posterior capsule rupture by blunt ocular trauma. J Cataract Refract Surg. 1997;23:139-140.

15. El-Gendy A, Rahman I, Mahmood U, Nylander A. Traumatic rupture of the posterior capsule resulting in complete posterior prolapse of the lens with subsequent resolution of high myopia. $J$ Cataract Refract Surg. 2006;32:893-894.

16. Wolter JR. Coup-contrecoup mechanism of ocular injuries. Am J Ophthalmol. 1963;56:785-796.
Clinical Ophthalmology

\section{Publish your work in this journal}

Clinical Ophthalmology is an international, peer-reviewed journa covering all subspecialties within ophthalmology. Key topics include: Optometry; Visual science; Pharmacology and drug therapy in eye diseases; Basic Sciences; Primary and Secondary eye care; Patient Safety and Quality of Care Improvements. This journal is indexed on

Submit your manuscript here: http://www.dovepress.com/clinical-ophthalmology-journal

\section{Dovepress}

PubMed Central and CAS, and is the official journal of The Society of Clinical Ophthalmology (SCO). The manuscript management system is completely online and includes a very quick and fair peer-review system, which is all easy to use. Visit http://www.dovepress.com/ testimonials.php to read real quotes from published authors. 